\title{
Segregated bike lanes are safest for cyclists
}

$\mathrm{D}$ edicated bike lanes reduce crashes and injuries, but not all bike infrastructure is created equal, and cyclists need to learn how to share space, say experts who have studied cycling safety.

Evidence is mounting that bike lanes reduce overall injuries and deaths, though the lanes pose various degrees of risk. Safer lanes are those physically segregated from motor vehicles, while other bike lanes or multi-use paths have no physical barriers for protection, and pose different risks cyclists may not be aware of, says Dr. Meghan Winters. Winters is the lead author of a recent Canadian Journal of Public Health study on risk perceptions of bike infrastructure (CJPH 2012;103:S42-7). Her research concludes that risk perceptions surrounding cycling are sometimes at odds with observed risk.
Winters and her colleagues surveyed 690 cyclists who went to emergency departments in Toronto, Ontario, and Vancouver, British Columbia. They calculated the observed risk of certain bike infrastructure using a case-crossover study design that compared the characteristics of a site where a cycling injury occurred to control sites along the route. The researchers calculated perceived risk of different infrastructure types based on the injured cyclists' response to the question: "How safe do you think this site was for cyclists on that trip?"

The researchers found general agreement between the cyclists' perception of risk and the risk they observed at the injury sites, with some discrepancies. Cyclists perceived multi-use paths where cyclists share space with walkers and other cyclists to be lower-risk than the researchers observed them to be, while the cyclists perceived that segregated bike lanes were higher risk than observation assessed them to be.

Winters believes cyclists perceived the segregated bike lanes as higher risk because they are new and people surveyed did not have as much experience using them. Cyclists may perceive multi-use paths as safer than they actually are because they forget that although they won't get hit by cars, they may collide with pedestrians, other cyclists or obstacles on the path.

Dr. Steven Friedman, a coauthor with Winters and a Toronto emergency department physician, says many of the cycling injuries he sees are the result of shared routes between bikes and motor vehicles. The result is what he calls a "nudging accident," where a cyclist may have been riding appropriately, but

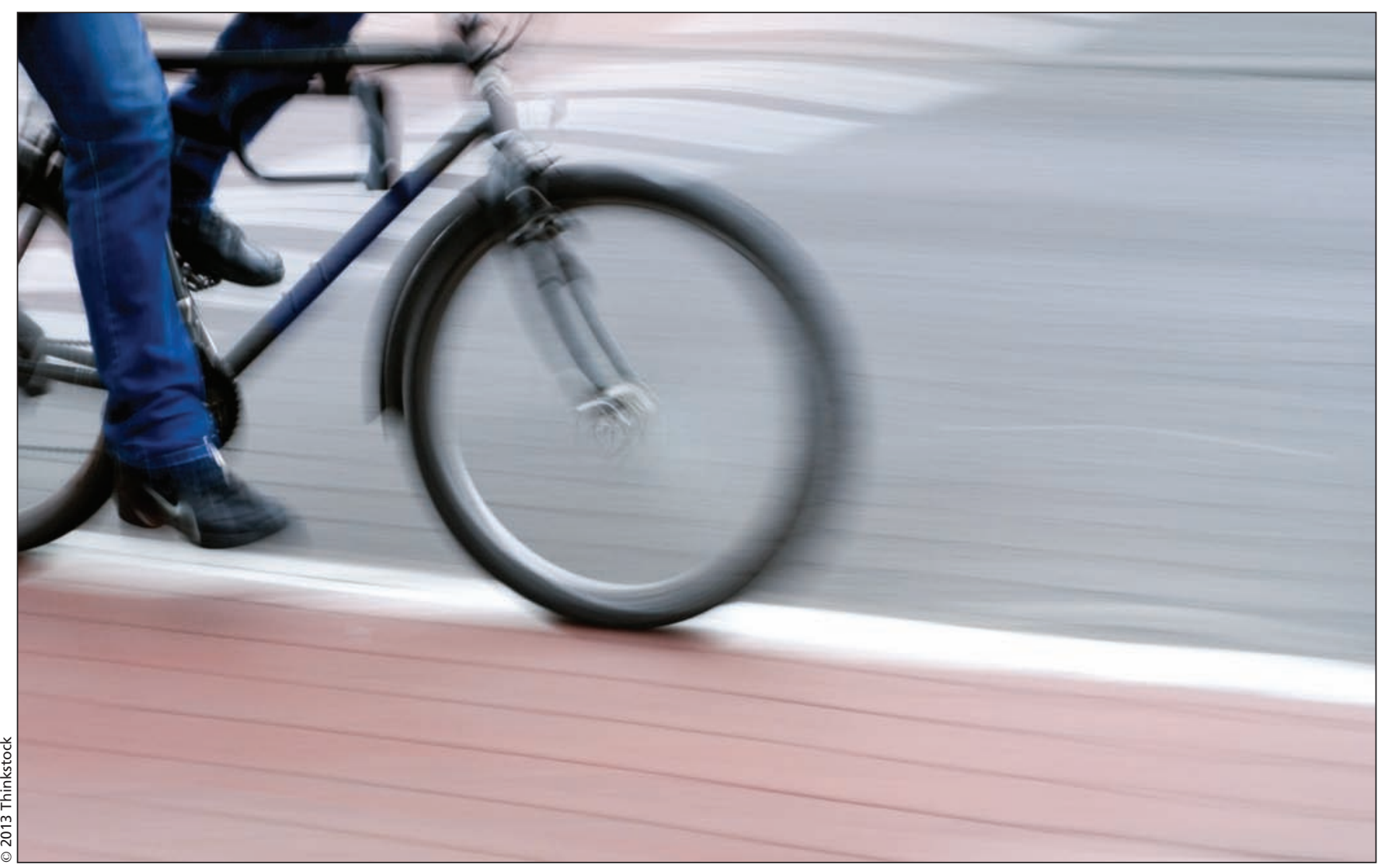

Bike lanes reduce overall injuries and deaths, though lanes with no physical barriers pose different risks. 
an obstacle in the lane nudges him or her towards a vehicle or another dangerous obstacle.

Still, cycling is not very dangerous, in Friedman's opinion. "Relatively speaking, I think we do many other harmful things like driving other types of motor vehicles."

Transport Canada statistics back up Friedman's opinion. According to the department's most recent statistics on motor vehicle traffic collisions, bicyclists accounted for just 60 fatalities, or $2.7 \%$.

But to ride safely in bike lanes, cyclists need to have skills that will protect. "Riders need to know how to interact with cars and other cyclists in the lanes," says Chuck Glover, a selfdescribed 56-year-old "commuter with an attitude." Glover is a CAN-BIKE
National Examiner who has taught more than 70 cycling safety courses in $\mathrm{BC}$ and the Yukon. CAN-BIKE is a national cycling education program that has been offering courses to adults and children since 1985 .

"The education component is most important when it comes to safe cycling," says Andy Wilson, CAN-BIKE coordinator at the Canadian Cycling Association. "Most people know how to ride a bicycle, but how to ride effectively in traffic is less well known."

Learning how to share spaces will continue to be a challenge in most urban areas in Canada, says Meghan Whitehead, project engineer at MMM Group Ltd., a Canadian planning, engineering and management firm. The company recently developed Ontario's first reference guide for bike facilities,
Ontario Traffic Manual Book 18: Bicycle Facilities, for engineers, planners and designers.

Streets were not originally designed to accommodate all potential users, she points out, especially since the first users in some municipalities were horses and buggies and until recently planners never imagined bike lanes.

Even with the challenges of sharing space safely, the benefits of biking are likely to outweigh the risks, says Friedman. Commuting by bike a few times a week gives people a greater chance of meeting Canada's physical activity guidelines, which recommend a weekly minimum of 150 minutes of aerobic physical activity for adults aged 18-64 years. - Emma Cohen, Ottawa, Ont.

CMAJ 2013. DOI:10.1503/cmaj.109-4468 